\title{
Psychological features of communicative personality behavior in the Internet space
}

\author{
Irina Luchinkina ${ }^{1 *}$ Wen Guanxu ${ }^{2}$ \\ ${ }^{1}$ Crimean Engineering and Pedagogical University, 295015 Simferopol, Russia \\ 2 Jiangsu Normal University, 221009, Xuzhou, China
}

\begin{abstract}
The article determines that belonging to one type or another of a person's communicative behavior in the Internet space is determined by a specific ratio of psychological factors namely: a combination of cognitive, motivational, affective components of a person's communicative behavior in the Internet space and the level of constructive-destructive behavior. The author proposes a typology of communicative behavior of a person depending on the type of cognitive distortion: destructive types of communicative behavior of a person in the Internet are based on cognitive distortions such as depreciation of the positive, mental filter, overgeneralization, dichotomous thinking, and catastrophization. The psychological characteristics of users conducting provocative activities on the network are investigated; prone to provocative online activities; ascribing to themselves the conduct of provocative activities in the network; not leading provocative online activities.
\end{abstract}

\section{Relevance}

Communicative activities in the Internet space, the implementation of the norms and rules of communicative behavior, a variety of forums, social networks contribute to the satisfaction of various human needs, including the need for communication, identification, selfaffirmation. At the same time, social networks, online communities, forums, chats contain content, often offering conflicting, unverified information that affects the user's personality in different ways.

Often, communication participants become victims or authors of fake news, provocative comments, trolling attacks, which can lead to a distortion in the perception of information, and subsequently, to a violation of the communication process and personal deviations, and sometimes suicide. In this regard, psychological studies of the cognitive, affective, motivational components of virtual communicative behavior are great importance.

\section{Statement of the primary material}

\footnotetext{
* Corresponding author: miss_luchinkina@mail.ru
} 
In psychological literature, communicative behavior in both real and virtual space is considered from the point of view of several approaches. Representatives of the first approach (A.P. Egides, M.E. Litvak, and T.G. Vatolina) communicative behavior is considered as a situational manifestation of certain reactions, human characteristics [1, 2, 3, 4].

Representatives of the second approach (A.I. Luchinkina, V.P. Morozov) regard communicative behavior as a process that facilitates the adaptation of an Internet user on the network. These concepts are most relevant for our study, because according to the authors, communicative behavior and its orientation are associated with the socio-psychological characteristics of the user of the Internet space $[5,6,7]$.

The cognitive components of a person's communicative behavior, in our opinion, are primarily expressed in cognitive distortions described by cognitive psychologist and psychotherapist A. Beck [8, 9].

Describing cognitive shifts, A.A. Aleksandrov notes that each cognitive distortion has its own program, which affects the determination of the method of processing information and the resulting behavior [10]. Cognitive personality distortions are formed because of dysfunctional thoughts that are in the cognitive patterns of a person [11].

As part of the study of the components of communicative behavior, we noted studies of motivation, psychological characteristics of Internet users and their activities. The most relevant of the modern concepts of motivation in virtual space is the concept of A.I. Luchinkina [12]. Therefore, in the network the user has motives available for implementation in real and virtual space; motives that are hardly realized outside the Internet space or inaccessible to the real space as a whole. The author proposes to consider the motives of staying on the network, each of which has its own characteristics of communicative behavior [12].

Attempts to analyze the affective component of communicative behavior are reflected in studies of the emoticon. An important characteristic of speech in virtual space was its saturation with graphic content, which is used to express emotional states. As noted, in the Internet space appeared emoticons which are dictionaries of graphic symbols expressing emotions. For example, “((" expresses sadness, “:)" means joy, “: *” means kiss, “) 0” means trolling, etc. Such characters are universal for all users; however, they do not always coincide with the user's real emotion.

As part of the study of the motivational component of communicative behavior, existing works are reduced to the study of a situational motive for communicating. However, the motivation of communicative behavior, in our opinion, is a stable characteristic and is expressed not only in online dialogue, but also in non-verbal and behavioral manifestations: creating a page image, features of the choice of the interlocutor, conducting destructive or constructive communication.

According to the research, the affective component of the communicative behavior of the person in the Internet space includes, most often, the need for communication, affiliation, and self-affirmation. Communicative attitudes, user reflexivity are poorly studied, however, these parameters, in our opinion, are able to influence the course of communication.

\section{Methods and results of the study}

The study was conducted in real space (490 people) and in virtual space (640 people). The importance of distinguishing between samples in virtual and real spaces is dictated by the fact of greater anonymity of the study in the online mode. An empirical study involved the study of the motivational, cognitive, affective components of communicative behavior.

At the first stage, using the author's questionnaire, content analysis of pages and selfreports, the "Directivity" scale of the "Personality in Virtual Space" methodology by A.I. Luchinkina, all respondents in the sample were divided into 4 groups in relation to 
provocative activities in the network. At the stage of the stating experiment, from 200 to 220 respondents of each indicated group were selected using the random number method.

At the second stage, the components of a person's communicative behavior in the Internet space are empirically investigated: cognitive, motivational, and affective. At this stage, the following methods were used: the "Personality in Virtual Space" methodology (A. I. Luchinkina), the "Identification of Awareness of the Various Components of a Motive" methodology (E.P. Ilyin) to study the motivation for being on the network. Were used author's research questionnaire "Cognitive distortion during online communication" to study dominant cognitive distortions of personality; diagnostic methodology of a communicative installation (V.V. Boyko) to identify the characteristics of the cognitive component of communicative behavior in the Internet space. Also were used a diagnostic technique for the level of development of reflexivity (A.V. Karpov) to identify the characteristics of the emotional-volitional sphere of communicants, content analysis; G. Eysenck's methodology "Self-assessment of mental states".

As mentioned above, according to the results of the study, all respondents in the sample were divided into 4 groups: leading provocative activities in the network ( 279 people); prone to provocative activity in the network (200 people); ascribing to themselves the conduct of provocative activities in the network (217); not conducting provocative activities on the network (434 people). At the stage of the stating experiment, from 200 to 220 respondents of each indicated group were selected using the random number method.

The results of the study of the motivational component of the communicative behavior of the person in the Internet space among the respondents of the selected groups are shown in Table 1.

Table 1. Distribution of leading motives among respondents with various types of communicative behavior in the Internet space (1 position).

\begin{tabular}{|c|c|c|c|c|}
\hline \multirow[b]{2}{*}{$\begin{array}{l}\text { Motives for } \\
\text { network } \\
\text { activity (in } \\
\text { absolute } \\
\text { numbers) }\end{array}$} & \multicolumn{4}{|c|}{ Groups of respondents } \\
\hline & $\begin{array}{l}\text { Leading } \\
\text { provocative } \\
\text { online } \\
\text { activities } \\
(220 \\
\text { people })\end{array}$ & $\begin{array}{c}\text { Prone to } \\
\text { provocative } \\
\text { online activities } \\
\text { (200 people) }\end{array}$ & $\begin{array}{l}\text { Ascribing to } \\
\text { themselves the } \\
\text { conduct of } \\
\text { provocative } \\
\text { activities in the } \\
\text { network } \\
\text { (217 people) }\end{array}$ & $\begin{array}{l}\text { Not conducting } \\
\text { provocative } \\
\text { online activities } \\
(220 \text { people })\end{array}$ \\
\hline $\begin{array}{l}\text { Motive for } \\
\text { Presence }\end{array}$ & 17 & 34 & 49 & 189 \\
\hline $\begin{array}{l}\text { Contribution } \\
\text { motive }\end{array}$ & 15 & 66 & 201 & 67 \\
\hline $\begin{array}{l}\text { The motive of } \\
\text { personal space }\end{array}$ & 45 & 13 & 67 & 156 \\
\hline $\begin{array}{l}\text { Replication } \\
\text { motive }\end{array}$ & 82 & 167 & 34 & 12 \\
\hline $\begin{array}{c}\text { The motive } \\
\text { for becoming } \\
\text { a role }\end{array}$ & 218 & 36 & 19 & 23 \\
\hline
\end{tabular}


As can be seen from Table 1, in the group of users conducting provocative activities, the most pronounced is the motive for becoming a role, in contrast to other groups. Atypical motives for this group of respondents were also identified: replication motive; the motive of personal space, the motive of the contribution, and the motive of the indicated presence. As a rule, respondents in this group tend to focus more on internal factors (I like it, I like to do it). In the group of users inclined to conduct provocative activities, the most frequently encountered was the replication motive, while in the remaining groups of respondents medium and low values on the specified scale were revealed. However, in the course of the analysis, respondents were identified who are characterized by the motive of the indicated presence; personal space motive; the motive of becoming a role. As a rule, respondents in this group tend to focus more on their needs (attracted).

For users who ascribe to themselves the conduct of provocative activities in the network, at least the contribution motive is characteristic. Atypical motives for this group of respondents were identified: the motive of the indicated presence; replication motive; personal space motive; the motive of becoming a role. As a rule, respondents in this group tend to focus more on their needs (I have long wanted to, there was an occasion), realize certain goals (prove to myself that I can).

In the group of users who are not conducting provocative activities on the network, the most pronounced are the motive of the indicated presence, the motive of personal space. The atypical motives for this group of respondents are the contribution motive, the replication motive, the incarnation motive. As a rule, respondents in this group tend to focus more on internal factors (you need to put yourself in the place of another).

The results of the study of the cognitive component of communicative behavior.

The highest values on the scales of "Depreciation of the positive", "Thought filter", "Overgeneralization" were revealed among the group of respondents conducting provocative activities in the network, while the remaining values on the indicated scales were revealed in the other groups of the experimental sample. However, atypical cognitive distortions were revealed for this group of the sample: dichotomous thinking, catastrophization, emotional justification, labeling, reading thoughts, personalization, and commitment.

A group of respondents prone to provocative activities in the network, as a rule, has cognitive distortions of the type of dichotomous thinking, labeling, unlike other groups. Dichotomous thinking is expressed in the perception of information in black and white: either good or bad. However, atypical cognitive biases were identified for this group of respondents: catastrophization; depreciation of the positive; emotional justification; mental filter; reading thoughts; personalization; commitment; overgeneralization.

The most common cognitive distortions in the group of respondents attributing themselves to the conduct of provocative activities in the network are catastrophization, reading of thoughts, unlike other groups of the sample. Atypical, however, cognitive biases for this group of respondents are dichotomous thinking, depreciation of the positive, emotional justification, labeling, mental filter, personalization, commitment, and overgeneration.

In the group of respondents who do not conduct provocative activities on the network, cognitive distortions are more pronounced as emotional justification, personalization, and commitment, in contrast to other groups. Rarely found cognitive biases for these respondents are dichotomous thinking; catastrophization; depreciation of the positive; labeling; mental filter; reading thoughts; overgeneralization.

The results of the study of the affective component of communicative behavior are shown in Figure 1. 


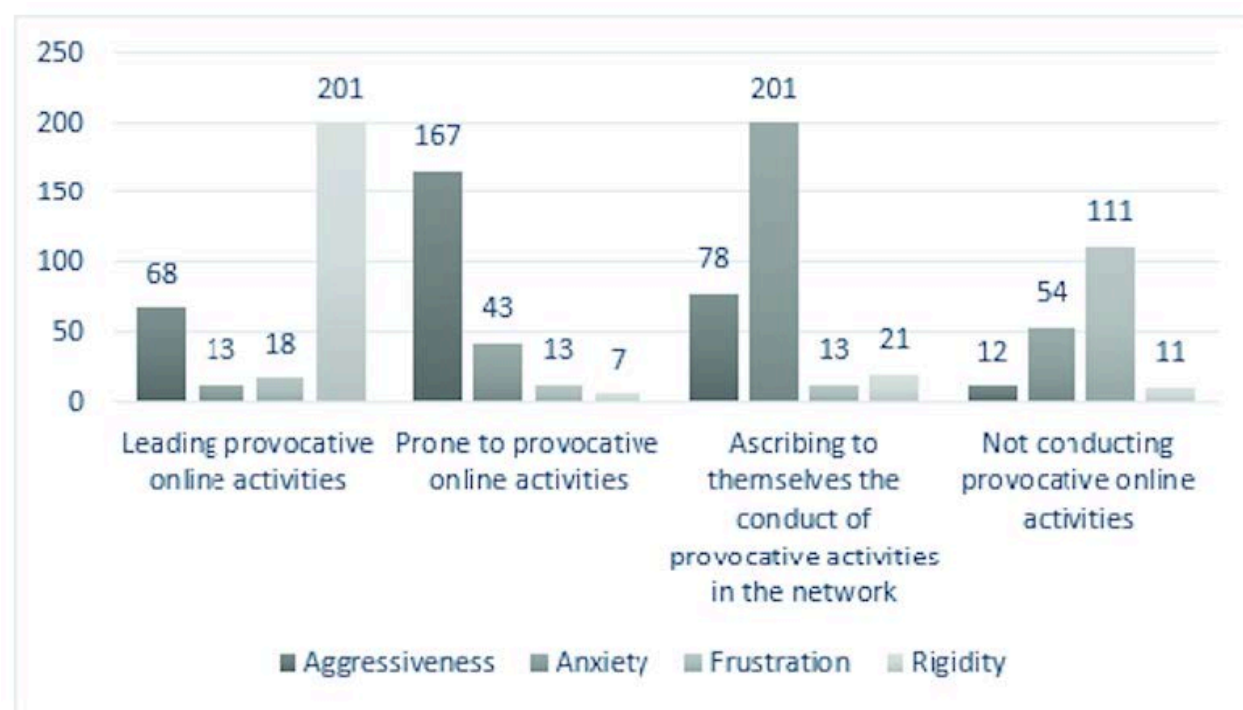

Fig. 1. Distribution of mental states among respondents with various types of communicative behavior in the Internet space (first position)

As can be seen in Figure 1, users who conduct provocative activities on the network are usually characterized by rigidity and aggressiveness. Mental states atypical for this group were revealed: anxiety, frustration.

Respondents prone to provocative online activities are characterized by aggressiveness, unlike other groups. Mental states atypical for this group were revealed: anxiety, frustration, rigidity.

The most common mental state in the group of respondents attributing themselves to conducting provocative activities on the network is anxiety. However, in the course of the study atypical mental conditions were noted for this group of respondents: aggressiveness, frustration, rigidity.

In the group of respondents who do not conduct provocative activities on the network, frustration is more pronounced, in contrast to other groups. Mental conditions atypical for this group were revealed: anxiety, rigidity.

The distribution of communicative attitudes, types of reflexivity according to the direction of communicative behavior, in the Internet space showed the following results: the most encountered communicative attitude in the group of respondents conducting provocative activities on the network is veiled cruelty in relation to people, judgments about them, grumbling, in contrast from other groups of the experimental sample. As a rule, respondents in this group are characterized by a low level of reflexivity in general. Most often, open cruelty in relations with people is noted among a group of respondents prone to provocative activities on the network, in contrast to other groups. As a rule, retrospective reflection is expressed among the respondents of this group.

The most common communicative attitude in the group of respondents ascribing to themselves the conduct of provocative activities on the network is substantiated negativity in judgments about people. As a rule, situational reflection is expressed among the respondents in this group. In the remaining three groups of the experimental sample, low indices on the specified scale were obtained.

The study showed a reliable relationship between individual mental states and cognitive distortions: rigidity and cognitive distortions such as the depreciation of a positive, mental 
filter, overgeneralization; anxiety and dichotomous thinking, labeling and aggressiveness; frustration and emotional depreciation, personalization.

Reliable connections between some communicative attitudes and certain cognitive errors were revealed: veiled cruelty in relations with people and cognitive distortions such as devaluation of a positive, mental filter and overgeneralization; grumbling and cognitive distortions such as the depreciation of a positive, mental filter and overgeneralization; open cruelty in relations with people and dichotomous thinking, labeling; substantiated negativism in judgments and catastrophization, reading of thoughts; the presence of negative personal experience in communicating with others and emotional depreciation, personalization.

\section{Conclusion}

Thus, the communicative behavior of a person in the Internet space has its own structure and is determined by the characteristics of cognitive, motivational and affective factors. The cognitive component of a person's communicative behavior in the Internet space includes cognitive distortions; the motivational component includes the motives of staying on the Web, the personality orientation in communication, the degree of awareness of the individual components of the motive; the affective component is represented by mental states (frustration, rigidity, aggressiveness, and anxiety), communicative attitudes, and reflection. The study revealed that there are differences within each component of communicative behavior for each of the groups.

Within the cognitive component, the following differences are noted: among the group of respondents conducting provocative activities on the network, the most pronounced is the depreciation of the positive, mental filter, overgeneration; among a group of respondents prone to provocative activities on the network, dichotomous thinking, labeling, and that are expressed; among the group of respondents attributing themselves to provocative activities on the network, catastrophization, reading of thoughts are expressed; for a group of respondents who are not conducting provocative activities on the network, emotional justification, personalization, and commitment are expressed.

\section{References}

1. A. Egides, Labyrinths of communication, or how to learn to get along with people (Astpress book, Moscow, 2002)

2. M.E. Litvak, Command or obey? Management Psychology (Phoenix, Rostov-on-Don, 2010)

3. K. Thomas, Models of experiments in social psychology and applied research (SocioPsychological Center, Moscow, 1996)

4. T.G. Vatolina, Concept 8, 1-6 (2015)

5. A.I. Luchinkina, Human. Science. 1, 54-62 (2016)

6. A.I. Luchinkina, Prob. of M. P. Ed. 51-1, 311-317 (2016)

7. V.P. Morozov, Inst. Psychol., 274-307 (2014)

8. A. Beck, Cognitive Therapy for Depression (Piter, St. Petersburg, 2003)

9. A. Beck, Cognitive Psychotherapy for Personality Disorders (Piter, St. Petersburg, 2019)

10. A.A. Aleksandrov, Psychodiagnostics and psychocorrection (Piter, St. Petersburg, 2008)

11. A.A. Aleksandrov, Integrative Psychotherapy (Piter, St. Petersburg, 2009)

12. A.I. Luchinkina, Sc. Note. 2 (4), 137-140 (2016) 